DOI 10.37882/2223-2982.2020.09-2.11

\title{
МИЛИТАРНЫЕ И СПОРТИВНЫЕ МЕТАФОРЫ ПРИ СОЗДАНИИ ОБРАЗА КРЫМА В ЗАРУБЕЖНЫХ И РОССИЙСКИХ СМИ
}

\section{MILITARY AND SPORT METAPHORS IN CREATING THE CRIMEA'S IMAGE IN THE FOREIGN AND RUSSIAN MEDIA}

\section{Kurbanov}

Summary:The article gives a comparative analysis of metaphorical models used to create the Crimea's conceptual image in the contemporary media texts of the English and Russian languages. Special attention is paid to military and sport metaphors, which create a fundamentally opposite image of the considered sphere. The article explains the motives for using these or those models.

Keywords: cognitive linguistics, metaphorical model, source (vehicle) sphere, military metaphors, sport metaphors.
Ц елью настоящей статьи является сопоставительное исследование метафорических моделей, используемых для концептуализации образа Крыма енных англоязычных и русскоязычных текстах СМИ на примере милитарных и спортивных метафор.

Материалом исследования являются новостные статьи, посвященные крымской тематике из русскоязычных и англоязычных СМИ в период с 2014 по 2020 год.

Общеизвестно, что в рамках когнитивной лингвистики язык рассматривается как общий когнитивный механизм, связанный с языковыми проявлениями человеческого мышления. В своих исследованиях представители когнитивной лингвистики отошли от традиционного понимания метафоры как средства украшения речи и рассматривают ее в качестве средства выражения мысли и познания мира (см. монографию Джорджа Лакоффа и Марка Джонсона «Метафоры, которыми мы живем») [11]. В основе метафор лежат не объективно существующие категории, а сформировавшиеся в сознании человека концепты. Концептуальная метафора особенно характерная для публицистической речи, т. к. позволяет поновому объяснить концепты какой-либо сферы, привлекая при этом понятийную структуру совершенно другой сферы.

При характеристике метафорических моделей важно указать следующие признаки: исходную понятийную область, новую понятийную область, типовые сценарии данной модели и относящиеся к ней фреймы, составляющие каждый фрейм типовые слоты, и компонент, свя-
Курбанов Ибрагим Алиевич

к.филол.н., профессор, Сургутский государственный университеm ibragimkurbanov@mail.ru

Аннотация: В статье проводится сопоставительное исследование метафорических моделей, используемых для концептуализации образа Крыма в современных англоязычных и русскоязычных текстах СМИ. Особое внимание уделяется милитарной и спортивной метафорам, создающим кардинально противоположное изображение сферы-магнита, объясняются мотивы использования тех или иных моделей.

Ключевые слова: когнитивная лингвистика, метафорическая модель, сфераисточник, милитарная метафора, спортивная метафора.

зывающий первичные и вторичные значения охватываемых данной моделью единиц.

В данной статье нами рассматриваются такие понятийные сферы как «Война» и «Игра и спорт».

Продуктивным способом концептуализации образа Крыма является милитарная метафора. Причину представления Крыма в терминах войны мы видим в том, что за эту область земного шара всегда шла борьба из-за выгодного географического положения. Анализ материала показал, что в структуре данной метафорической модели присутствуют основные фреймы и входящие в их состав слоты, традиционно выделяемые в данной сфереисточнике.

Метафорическая модель «Крым - это война» в русском языке представлена фреймами «военное место», «военные действия» и «военное звание». Перейдем к анализу вербальной репрезентации данной модели.

Фрейм - военное место

Слот 1 - полигон

Пример 1. Таким образом, Крым может стать своеобразным полигоном для обкатки идеи объединения ФНС и ФТС. (РБК daily, 23 марта 2014).

Основанием для метафорического употребления лексемы «полигон» в отношении Крыма послужило его восприятие, прежде всего, как географического объек- 
та, места. Прототипическая функция полигона как места испытания оружия и техники позволяет судить о Крыме в качестве места испытания новой системы совместной работы налоговой и таможенной служб. Тем не менее, данный слот воспринимается отрицательно.

\section{Слот 2- авианосец}

Пример 2. Кроме того, украинский политик рассказал на ВBC, что Крымский полуостров после воссоединения с Российской Федерачией «превратился в военную базу, непотопляемый авианосец». (Московский комсомолеи, 15 мая 2019).

Изображение Крыма при помощи милитарных метафор «военная база» и «авианосец» основано на предположении о том, что после присоединения Крыма Россия разместила там свои войска и современные военную технику. Использование подобных милитарных метафор совместно с эмоционально-оценочной лексикой оказывает отрицательное воздействие на реципиента.

\section{Слот 3-передовая}

Пример 3. «Фактически Крым стал «передовой» в войне РФ сиивилизованным миром. Пока холодной войне», nишет кандидат наук госуправления. (Московский комсомолеи, 15 мая 2019).

Подобно тому, как передовая в войне является местом всех основных событий и самых ожесточенных боев, Крым для России стал местом «идеологической борьбы» или «метафорической войны» с отдельными западными странами. Соответственно, данный слот также воспринимается отрицательно.

$$
\text { Фрейм - военные Аействия }
$$

\section{Слот 1 - оборона}

Пример 4. Там Крым выстоял против большевиков в гражданскую, но не стал и фашистским государством, избавившись от диктатора-барона и обратившись в русскую республику. (Известия, 14 марта 2014).

Пример 5. Тогда откуда слухи о том, что Крым готовится к самообороне? (Известия, 24 февраля 2014).

Одним из основных действий в войне является оборона и защита своих территорий и интересов. Так, в данных примерах Крым олицетворяет собой храброго бойца, который выдержал натиск врага и защитил свою территорию. Данный слот воспринимается положительно.

\section{Слот 2-поражение}

Пример 6. Повторяет к возмущению нелегитимных ни с какой, кроме американской, точки зрения властей Украины и сочувствующего им российского "креативного класса», который рассматривает воссоединение Крыма едва ли не как личное поражение, что еще раз говорит разногласия у этих граждан не с Путиным, а с Россией и русским народом. (Известия, 6 марта 2014).

В любой войне есть две стороны: победитель и проигравший. В данном случае образ Крыма концептуализируется с помощью милитарной метафоры, представляя его как личное поражение определенной части населения России, выступающего против присоединения Крыма, в результате чего данная метафора оказывает отрицательное воздействие на реципиента.

\section{Фрейм - военное звание}

Пример 7. Крымская АССР в составе РСФСР существовала в 1921-1946 годах. Затем, после депортации многих коренных народов, Крым «разжаловали» в область и в таком качестве в 1954 году передали в состав УССР. (Известия, 17 апреля 2014).

В данном примере Крым изображается частью личного военного состава СССР и отожествляется с отдельно взятым военнослужащим, который был переведен начальством из высокого звания в более низкое. Использование такой милитарной метафоры производит отрицательный эффект на адресата.

В итоге делаем вывод, что модель «Крым - это война» в русскоязычных СМИ представлена всего несколькими фреймами, хотя каждый из них содержит множество разнообразных слотов, большинство которых порождают отрицательные прагматические смыслы, что объясняется восприятием войны как отрицательного социального явления.

Перейдем к детальному рассмотрению метафорической модели «Крым - это война» в англоязычных СМИ, где фигурируют идентичные русскому языку фрейMы.

\section{Фрейм - военное место}

\section{Слот 1 - плацдарм}

Пример 8. Through the virtual annexation of Crimea and the maneuvers of Russian troops along Ukraine's border, he has now deftly managed to give Russia a springboard to occupation of the balance of Ukraine. (Посредством виртуальной аннексии Крыма и маневров российских войск вдоль границы с Украиной он ловко предоставил России 
плацдарм для оккупации остальной Украины.) (The Baltimore sun, 24 мapma 2014).

Согласно определению С.И. Ожегова, плацдарм пространство, на котором подготавливается и развертывается военная операция [12, с. 472]. Таким образом, можно предположить, что в сознании читателей данной газеты Крым выступает отправной точкой для захвата всей Украины, что создает отрицательный эффект от рассматриваемой метафоры.

\section{Слот 2- передовая}

Пример 9. Crimea is the frontline of this silent war, writes Roland Oliphant. But in Moscow, the propaganda battle is being played out at full volume. (Крым - линия фронта этой тихой войны, пишет Роланд Олифант. Но в Москве пропагандистская битва разворачивается в полную силу.) (The Telegraph, 2 мapma 2014).

Функционирование данного слота в английском языке схоже с его функционированием в русском языке (см. пример № 3).

\section{Слот 3 - поле битвы}

Пример 10. Crimea is a battleground not only for neighbouring nations but for fast food chains it seems, with Burger King Russia announcing plans to open restaurants in the peninsula after McDonald's left due to 'unspecified manufacturing reasons.' (Похоже, что Крым является полем битвы не только для соседних стран, но и для сетей быстрого питания, и Burger King Russia объявляет о планах открыть рестораны на полуострове после ухода McDonald's из-за «неопределенных производственных причин».) (The Independent, 10 апреля 2014).

В данном случае метафоризация образа Крыма происходит посредством употребления речевой репрезентации, относящейся к сфере-источнику «поле битвы». Так, Крым предстает местом, где на постоянной основе идет борьба противоборствующих сил, что создает в сознании реципиента отрицательный образ рассматриваемого объекта.

\section{Фрейм - военные вействия}

\section{Слот 1 -захват}

Пример 11. Russian takeover of Crimea will not descend into war, says Vladimir Putin. (Российский захват Крыма не перейдет в войну, считает Владимир Путин.) (Тhe Guardian, 4 mapma 2014).

Данный слот может быть также представлен синонимичной вербальной репрезентацией "seizure". Изо- бражение Крыма как территории, захваченной Россией, вынуждает реципиента рассматривать данный регион исключительно в контексте войны, в результате чего данная милитарная метафора оказывает отрицательный эффект на читателя.

\section{Слот 2- защищать}

Пример 12. However, it is not clear just how Ukraine intends to defend Crimea, and spirit may not be enough. (Однако непонятно, как именно Украина намерена защищать Крым, и духа может не хватить.) (The Guardian, 9 марта 2014).

Настоящий слот в английском языке может быть также представлен синонимичными лексемами "to protect", "to safeguard", а его функционирование схоже с тем, что было нами рассмотрено в примерах № 4 и № 5.

На основании проведенного анализа модели «Крым - это война» в англоязычных СМИ делаем вывод, что данная модель представлена практически идентично, если сравнивать ее с русскоязычной моделью, и также создает в сознании адресата отрицательные прагматические смыслы, связанные с применением военных терминов при метафоризации Крыма.

Таким образом, делаем вывод, что концептуализация Крыма в терминах войны показывает, что для описания сложившейся на полуострове ситуации часто используются вербальные репрезентации, относящиеся к сфереисточнику «Война», чем подчеркивается опасность ситуации или бедственное положение полуострова. В связи с этим в обоих языках создаются отрицательные прагматические смыслы данной метафорической модели.

Далее нами выделяется модель, основанная на метафорическом переносе из понятийных сфер «Спорт» и «Игра» в ментальную сферу «Крым». Данный перенос возможен благодаря тому, что эти сферы оперируют такими концептами, как «участие», «лидер», «отыгрываться» и др. Кроме того, спорт и игры занимают особое место в человеческой деятельности, обладают высокой популярностью и большой силой эмоционального воздействия. Начнем с рассмотрения метафорической модели «Крым - это спорт / игра» в русскоязычных СМИ.

\section{Фрейм - эстафета}

Пример 13. 10 июля летний лагерь с длинным названием «Я гражданин и защитник великой страны» для детей om 12 до 18 лет откроется под Нижним Новгородом, позднее эстафету примут Волгоградская, Челябинская области и Республика Крым. (Известия, 10 июля 2014).

Подобно тому, как спортсмены, участвуя в эстафете, 
по очереди начинают свое участие в состязании, так и различные регионы страны часто по очереди проводят различные мероприятия, перенимают опыт их проведения друг у друга. В этот раз Крым не останется в стороне, что позволяет судить о лексеме «эстафета» как о дающей положительную метафорическую оценку изучаемому объекту.

\section{Фрейм - участие}

\section{Слот 1 -участвовать}

Пример 14. В данный момент существует единственный реальный вариант, по которому Крым может принять участие в чемпионате мира-2018, - это создание тренировочной базы для стран-участниц на период проведения предстоящего первенства. (Известия, 7 апреля 2014).

Метафорический перенос понятий из сферы-источника «Спорт» в ментальную сферу «Крым» становится возможным благодаря использованию выражения «принимать участие», которое совместно с ближайшим контекстом позволяет судить о Крыме как о спортсмене и воспринимать его положительно.

\section{Слот 2 - лидировать}

Пример 15. Несмотря на то, что крымская экономика находится в сложной ситуации, назвать ее безнадежной нельзя, уже в ближайшие годы Крым и Севастополь могут стать лидерами по темпам роста среди российских регионов. (Прайм, 15 апреля 2014).

Установление аналогии между ментальной сферой «Крым» и сферой-источником «Спорт» возможно при использовании лексемы «лидер», что также позволяет воспринимать Крым как спортсмена, участника соревнований, лидирующего в своем виде спорта, за счет чего создаются положительные прагматические смыслы данного слота.

\section{Слот 3 - отыгрываться}

Пример 16. Правда украинская армия теоретически может «отыграть» Крым, считает Целуйко. (Известия, 3 марта 2014).

Желание отыграться является естественным желанием проигравшего в игре. Если всю ситуацию в Крыму имплицитно описывать как спортивную или азартную игру, то логичным является желание Украины вернуть себе проигранное имущество, что, однако, не так просто. Таким образом, прагматические смыслы данного слота отрицательны.
На основании проведенного анализа можно сделать вывод, что метафорическая модель «Крым - это спорт / игра» в русском языке является довольно хорошо структурированной, а представленные в данной модели фреймы порождают в основном положительные прагматические смыслы, что объясняется общим положительным восприятием спорта и его полезностью для здоровья.

Рассмотрим метафорическую модель «Крым - это спорт / игра» в англоязычных СМИ, где она представлена несколько иными фреймами по сравнению с русскоязычными СМИ

\section{Фрейм - игра}

Пример 17. Ethnic Ukrainians interviewed outside the Ukrainian Orthodox cathedral of Vladimir and Olga said they refused to take part in the referendum, calling it an illegal charade stage-managed by Moscow. "We're just not going to play these separatist games," said Yevgen Sukhodolsky, a 41-year-old prosecutor from Saki, a town outside Simferopol. (Этнические украинцы, опрошенные у стен украинского православного собора Владимира и Ольги, заявили, что отказались участвовать в референдуме, назвав его незаконной шарадой, организованной Москвой. «Мы просто не собираемся играть в эти сепаратистские игры", - заявил Евгений Суходольский, 41-летний прокурор города Саки, расположенного недалеко от Симферополя.) (New York Post, 16 марта 2014).

В отношении процесса проведения референдума в Крыму часто используется выражение «сепаратистские игры» или «игры в шарады». Шарада, согласно словарю С.И. Ожегова, загадка, в которой загаданное слово делится на несколько частей - отдельных слов [12, с. 825]. Использование подобных выражений в отношении важного события в жизни полуострова описывает его как детскую забаву, создавая его отрицательное восприятие читателем статьи.

\section{Фрейм - участие}

Пример 18. Russia will hold nationwide parliamentary elections on 18 September, with Crimea taking part for the first time since its annexation. (Россия проведет всенародные парламентские выборы 18 сентября, причем Крым примет в них участие впервые с момента аннексии.) (The Guardian, 10 августа 2016).

Функционирование данного фрейма в английском языке схоже с рассмотренным выше примером № 14 в русском языке. 


\section{Фрейм - призовые места}

Слот 1 - чемпион

Пример 20. "According to [the Russian Federal State Statistics Service (Rosstat)], in terms of... growth in manufacturing production between 2014 and 2017, Crimea and Sevastopol were the champions," Alexander Skorobogatov, a professor at the Higher School of Economics in Saint Petersburg and author of a blog entitled Economics and Applications, told World Finance. («По данным [Федеральной службы государственной статистики России (Pосстат)], с точки зрения... роста промышленного производства в период с 2014 по 2017 год Крым и Севастополь были чемпионами», - сказал журналу "World Finance" Александр Скоробогатов, профессор Высшей школы экономики в СанктПетербурге и автор блога под названием «Экономика и ее приложения».) (World Finance, 28 октября 2019).

Использование данного слота в английском языке может считаться синонимичной репрезентацией слота «лидировать» (см. пример № 15) в русском языке, за счет чего данный слот также воспринимается положительно.

\section{Слот 2-второе место}

Пример 20. On the contrary, things are going better than ever: in Q1 2019, Crimea grew faster than any other region in Russia. Sevastopol, a city within Crimea that Russia administers separately, followed in second place. (Наоборот, дела идут лучше, чем когда-либо: в первом квартале 2019 года Крым рос быстрее, чем любой другой регион России. Севастополь, город в составе Крыма, которым Россия управляет отдельно, занял второе место.) (World Finance, 28 октября 2019).

Успешным результатом участия в спортивных соревнованиях считается также и второе место. Так, в данном примере Крым имплицитно подразумевается чемпио- ном соревнований, в то время как Севастополю, отдельному субъекту РФ, удалось стать в данном соревновании вторым, что создает положительный эффект от использования подобной метафоры.

Можно сказать, что данная модель в англоязычных сми частично совпадает с русскоязычной моделью «Крым - это спорт / игра» по своей фреймо-слотовой структуре. Однако создаваемые ей прагматические смыслы могут быть как положительными, так и отрицательными в случае упоминания несерьезности игры или нарушения правил.

Концептуализация Крыма и крымской реальности с применением терминов спорта и игры показывает, что события, происходящие в Крыму, воспринимаются как состязание сторон, а сам Крым - как спортсмен, соревнующийся с другими регионами России. Прагматические смыслы данной метафорической модели в основном положительные в обоих языках, за исключением некоторых словоупотреблений, относящихся к сфере-источнику «Игра/азартная игра», что в целом объясняется полезностью спорта для жизни.

В итоге, делаем вывод, что милитарная и спортивная метафоры, которые можно объединить в разделе социальной метафоры, достаточно продуктивны в обоих рассматриваемых языках. Частота обращения к социальным метафорическим моделям при создании образа Крыма в русском языке составила $17 \%$, а в английском $-27 \%$. Нами были рассмотрены такие сферы социальной жизни человека как «Война» и «Игра и спорт», первая из которых создаёт отрицательный образ Крыма, что связано с жестокостью войны, в то время как сфера-источник «Спорт» создает положительные прагматические смыслы в отношении Крыма. Можно предположить, что это обусловлено общей полезностью спорта и радостью выигрыша в соревнованиях.

\section{ЛИТЕРАТУРА}

1. Интернет-портал «Прайм» [Электронный ресурc]. URL: https://1prime.ru/ (дата обращения 15.12.2018)

2. Интернет-портал газеты «Известия» [Электронный ресуpc]. URL: https://iz.ru/ (дата обращения 15.10.2018)

3. Интернет-портал газеты «Московский комсомолец» [Электронный ресурc]. URL: https://mk.ru/ (дата обращения 15.10.2018)

4. Интернет-портал газеты «РБК daily» [Электронный ресурc]. URL: https://www.rbc.ru/newspaper/ (дата обращения 15.12.2018)

5. Интернет-портал газеты “New York Post” [Электронный ресурc]. URL: https://nypost.com/ (дата обращения 25.11.2019)

6. Интернет-портал газеты “The Baltimore Sun” [Электронный ресурc]. URL: http://www.baltimoresun.com/ (дата обращения 26.11.2019)

7. Интернет-портал газеты “The Daily Telegraph" [Электронный ресурc]. URL: http://www.telegraph.co.uk/ (дата обращения 29.11.2018)

8. Интернет-портал газеты “The Guardian” [Электронный ресурc]. URL: https://www.theguardian.com/international (дата 0бращения 29.11.2018)

9. Интернет-портал газеты “The Independent” [Электронный ресурс]. URL: https://www.independent.co.uk/ (дата обращения 27.11.2019)

10. Интернет-портал журнала “World Finance” [Электронный ресурc]. URL: https://www.worldfinance.com/ (дата обращения 29.11.2019)

11. Лакофф, Дж., Джонсон, М. Метафоры, которыми мы живем: Пер. с англ. / Под ред. и с предисл. А.Н. Баранова. - М.: Едиториал УРСС, 2004. - 256 с.

12. Ожегов, С.И. Толковый словарь русского языка: 80000 слов и фразеологических выражений / С.И. Ожегов, Н.Ю. Шведова; Российская академия наук. Институт русского языка им. Виноградова. - 4-е изд., дополненное. - М.: 000 «ИТИ ТЕХНОЛОГИИ», 2003. - 944 с.

(c) Курбанов Ибрагим Алиевич (ibragimkurbanov@mail.ru). 